\title{
Effect of sintering temperature on microstructure and nonlinear electrical characteristics of $\mathrm{ZnO}$ varistor
}

\author{
Ahmed Bouchekhlal* and Farida Hobar \\ Microsystems and Instrumentation Laboratory \\ University of Constantine 25017, Algeria \\ *bouchekhlalahmed@umc.edu.dz
}

Received 1 March 2018; Revised 29 March 2018; Accepted 3 April 2018; Published 7 May 2018

\begin{abstract}
The nonlinear properties of ZBMCCS-based varistors, which are composed of $\mathrm{ZnO}-\mathrm{Bi}_{2} \mathrm{O}_{3}-\mathrm{MnO}_{2}-\mathrm{Cr}_{2} \mathrm{O}_{3}-\mathrm{Sb}_{2} \mathrm{O}_{3}-\mathrm{Co}_{3} \mathrm{O}_{4}$ and $\mathrm{SiO}_{2}$ are studied inrelation to sintering temperature, in the range of $1280-1350^{\circ} \mathrm{C}$. The samples are investigated for grain morphology by using scanning electron microscope (SEM). These samples were examined by using X-ray diffraction patterns (XRD) and DC electrical measurements. X-ray diffraction analysis of the samples show the presence of $\mathrm{ZnO}, \mathrm{Zn}_{2} \mathrm{SiO}_{4}$ willemite phase and $\mathrm{Co}_{2.33} \mathrm{Sb}_{0.67} \mathrm{O}_{4}$ spinel phases. The average grain size of $\mathrm{ZnO}$ increased as the sintering temperature increased from 2.57 to $6.84 \mu \mathrm{m}$. In the examined temperature range, the breakdown field decreased from 2992 to $127 \mathrm{~V} / \mathrm{cm}$ with the increase of sintering temperature. This system gives a relatively high nonlinearity coefficient $\alpha=33.61$ (at a sintering temperature of $1280^{\circ} \mathrm{C}$ ) with a low leakage current of $0.21 \mathrm{~mA} / \mathrm{cm}^{2}$.
\end{abstract}

Keywords: $\mathrm{ZnO}$ varistor ceramics; microstructure; nonlinear coefficient; sintering temperature.

\section{Introduction}

Zinc oxide varistors are ceramic semiconductor devices with high nonlinear current-voltage characteristics. This latter and the energy absorption capability are the two most important parameters of the $\mathrm{ZnO}$ varistor. ${ }^{1}$ The nonlinearity coefficient is defined as:

$$
I=K V^{\alpha},
$$

where $K$ is a constant, $\alpha$ is the nonlinear coefficient. $\mathrm{ZnO}$ varistors are used as surge protection devices in different electrical and electronic circuits, where many studies have already focused on electrical properties of varistor. Various techniques of elaboration have been used, such as ceramic method and chemical method. The size of the grains and the homogeneity of the microstructure are essential elements for the development of efficient $\mathrm{ZnO}$ varistors. In this context, the choice of a ceramic method makes it possible to envisage obtainment of fine grains as well as a good dopant distribution. The varistor devices were formed by sintering $\mathrm{ZnO}$ powder with a number of other metal oxides of small amount $\left(\mathrm{Bi}_{2} \mathrm{O}_{3}, \mathrm{MnO}_{2}, \mathrm{Co}_{3} \mathrm{O}_{4}, \mathrm{Cr}_{2} \mathrm{O}_{3}, \mathrm{Sb}_{2} \mathrm{O}_{3}, \mathrm{AL}_{2} \mathrm{O}_{3}\right.$ and $\mathrm{SiO}_{2}$, etc) where all these oxides are milled together before sintering. ${ }^{2}$ Each of them has a special function both in the sintering temperature and in the resulting varistor. The addition of $\mathrm{Bi}_{2} \mathrm{O}_{3}$ and $\mathrm{Cr}_{2} \mathrm{O}_{3}$ were needed to increase the breakdown voltage, ${ }^{3-5}$ and manganese and cobalt dopants enhance the degree of nonlinearity. ${ }^{4,6} \mathrm{Al}_{2} \mathrm{O}_{3}$ was added to increase the electrical conductivity of the zinc oxide grains. ${ }^{7}$ Shuai et al. have reported that $\mathrm{Cr}_{2} \mathrm{O}_{3}$ did not react with $\mathrm{ZnO}$ at such low sintering temperature of $950^{\circ} \mathrm{C} .^{8}$ The reactions between $\mathrm{ZnO}$ and oxide additives in high-temperature lead to the formation of different phases in the $\mathrm{ZnO}$ grain boundary. ${ }^{9}$ These phases are the spinel phase and the willemite phase. ${ }^{10}$ For this reason, sintering temperature is one of the most important parameters in making varistors, because approximately all properties of varistors are affected by temperature. More recently, published research has shown that the addition of $\mathrm{SnO}_{2}$ significantly influences $\mathrm{ZnO}$ grain growth, and nonlinear properties. ${ }^{11}$ In 2014, Guangliang Hu et al. studied the microstructure and the electrical properties of $\mathrm{MgO}$ doped $\mathrm{SnO}_{2}$ varistor ceramics. It indicates that $1350^{\circ} \mathrm{C}$ is the best sintering temperature for this system. ${ }^{12}$ Thus, Nahm investigated the microstructure and electrical properties of the $\mathrm{ZnO}-\mathrm{Pr}_{6} \mathrm{O}_{11}-\mathrm{Bi}_{2} \mathrm{O}_{3}$-based varistor ceramics with sintering changes in the range of $1100-1250^{\circ} \mathrm{C} .{ }^{13}$ There are no published reports studying the effect of the sintering temperature on the varistor properties in ZBMCCS-based varistor ceramics, especially, in the range of $1280-1350^{\circ} \mathrm{C}$.

The aim of this work is to investigate the effect of sintering temperature on the microstructure and electrical properties of the ZBMCCS-based varistors.

\section{Experimental Procedure}

\subsection{Sample preparation}

Reagent-grade raw materials were used in proportions of $96 \mathrm{~mol} \% \mathrm{ZnO}, 0.5 \mathrm{~mol} \% \mathrm{Bi}_{2} \mathrm{O}_{3}, 0.5 \mathrm{~mol} \% \mathrm{MnO}_{2}, 0.5 \mathrm{~mol} \%$ $\mathrm{Cr}_{2} \mathrm{O}_{3}, 1 \mathrm{~mol} \% \mathrm{Sb}_{2} \mathrm{O}_{3}, 0.5 \mathrm{~mol} \% \mathrm{Co}_{3} \mathrm{O}_{4}$ and $1 \mathrm{~mol} \% \mathrm{SiO}_{2}$.

This is an Open Access article published by World Scientific Publishing Company. It is distributed under the terms of the Creative Commons Attribution 4.0 (CC-BY) License. Further distribution of this work is permitted, provided the original work is properly cited. 
High-purity commercial $\mathrm{ZnO}$-micro (purity of 99.7\%), and the other oxides were mixed and homogenized in absolute ethanol, using porcelain balls within a polypropylene bottle for $24 \mathrm{~h}$. The mixture was dried at $100^{\circ} \mathrm{C}$ for $24 \mathrm{~h}$ and calcined in air at $750^{\circ} \mathrm{C}$ for $2 \mathrm{~h}$. The resulting powders are pressed into discs of $13 \mathrm{~mm}$ in diameter and $2 \mathrm{~mm}$ thickness at a pressure of $1000 \mathrm{~kg} / \mathrm{cm}^{2}$. The discs were sintered at four fixed different temperatures $1280^{\circ} \mathrm{C}, 1300^{\circ} \mathrm{C}, 1320^{\circ} \mathrm{C}, 1350^{\circ} \mathrm{C}$, for $2 \mathrm{~h}$ with heating and cooling rates of $5^{\circ} \mathrm{C} / \mathrm{min}$. These samples are labeled FB1, FB2, FB3 and FB4, respectively, in the following parts of the text. The size of the final samples were about $8 \mathrm{~mm}$ in diameter and $1.0 \mathrm{~mm}$ in thickness. Both sides of the sintered samples were polished and coated in a silver paste and ohmic contacts were formed by heating at $600^{\circ} \mathrm{C}$ for $10 \mathrm{~min}$ in air. The electrodes were $5 \mathrm{~mm}$ in diameter.

\subsection{Microstructure examination}

The microstructures of samples were examined via the scanning electron microscope (JEOL, JSM-6360LV). The average grain size $(D)$ was determined by the lineal intercept method using the following equation:

$$
D=1.56 \frac{L}{M N}
$$

where $L$ is the random line length on the micrograph, $M$ is the magnification of the micrograph, and $N$ is the number of grain boundaries intercepted by the lines. ${ }^{14,15}$

The phase composition of samples was characterized by means of X-ray diffraction (XRD) in D8 advance BRUKER diffractometer with $\mathrm{Cu}-\mathrm{K} \alpha(\lambda=1.54 \AA)$.

\subsection{Electrical measurement}

The electrical properties for sintered samples were performed with a Keithley 2015 digital multimeter and an Extra high voltage (Power supply) (LB2615-001, Australia). The current was recorded by increasing the applied voltage manually to characterize the electric field current density $(E, J)$ behavior of all samples. The nominal breakdown field $E_{B}=V_{1} \mathrm{~mA}$ $(\mathrm{V} / \mathrm{cm})$ was measured when the current flowing through the varistor is $1 \mathrm{~mA} / \mathrm{cm}^{2}$. Breakdown electrical field of varistors can be expressed by the following equation:

$$
E_{B}=\left(\frac{V_{\mathrm{gb}}}{D}\right),
$$

where $V_{\mathrm{gb}}$ is the average breakdown voltage per grain boundaries. From the measured values of $E_{B}$ and $D, V_{\mathrm{gb}}$ could be obtained. ${ }^{16}$

The leakage current $\left(I_{L}\right)$ is measured at $0.8 V_{B} \cdot{ }^{15,17}$ The nonlinear coefficient $\alpha$ is obtained by the following equation:

$$
\alpha=\frac{\log \left(\frac{J_{2}}{J_{1}}\right)}{\log \left(\frac{E_{2}}{E_{1}}\right)}=\frac{1}{\log \left(E_{2}-E_{1}\right)},
$$

where $E_{1}$ and $E_{2}$ are the electric fields corresponding to $J_{1}=1 \mathrm{~mA} / \mathrm{cm}^{2}$ and $J_{2}=10 \mathrm{~mA} / \mathrm{cm}^{2},{ }^{18}$ respectively.

\section{Results and Discussion}

\subsection{Microstructure analyses}

Figure 1 shows SEM micrographs of ZBMCCSS-based varistors sintered at different temperatures. The grain sizes of ZBMCCSS ceramic varistors were shown to increase from 2.57 to $6.84 \mu \mathrm{m}$ when the sintering temperature increases from $1280^{\circ} \mathrm{C}$ to $1350^{\circ} \mathrm{C}$. The detailed microstructural parameters are summarized in Table 1. It is clear that the sample FB1 has smaller average grain size than the others, which demonstrates that the higher sintering temperature has played an effective role in controlling the growth of the grains.

\subsection{X-ray powder diffraction}

The XRD patterns for all samples sintered with four different temperatures are given in Fig. 3. The XRD pattern reveals the presence of three diffraction peaks, namely, primary phase $\mathrm{ZnO}$ (JCPDS No. 065-3411), as the predominant compound and secondary phase willemite $\mathrm{Zn}_{2} \mathrm{SiO}_{4}$ (JCPDS No. 0371485) and spinel phase $\mathrm{Co}_{2.33} \mathrm{Sb}_{2.67} \mathrm{O}_{4}$ (JCDPS No. 150517). As can be seen in Fig. 3, it is revealed that the spinel
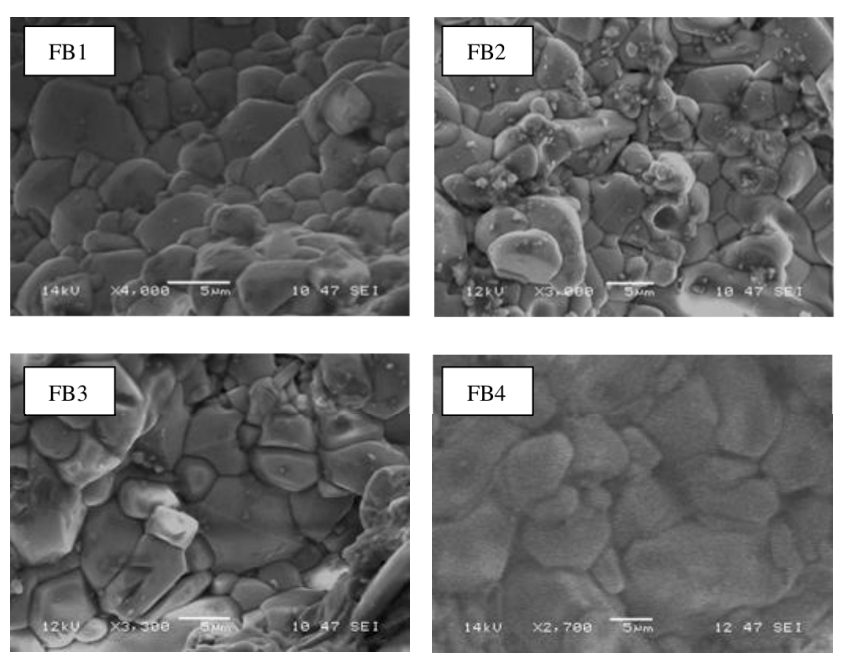

Fig. 1. SEM micrographs of the samples for different sintering temperatures.

Table 1. E-J and microstructure characteristic parameters of the samples for different sintering temperatures.

\begin{tabular}{lccrrcc}
\hline Samples & $\mathrm{T}^{\circ} \mathrm{C}$ & $\mathrm{D}(\mu \mathrm{m})$ & $E_{B}(\mathrm{v} / \mathrm{cm})$ & $\alpha$ & $V_{\mathrm{gb}}(\mathrm{v})$ & $I_{L}\left(\mathrm{~mA} / \mathrm{cm}^{2}\right)$ \\
\hline FB1 & 1280 & 2.57 & 2991.57 & 33.61 & 0.77 & 0.21 \\
FB2 & 1300 & 3.61 & 543.94 & 7.87 & 0.19 & 0.27 \\
FB3 & 1320 & 4.5 & 127.84 & 3.19 & 0.05 & 0.56 \\
FB4 & 1380 & 6.84 & 664.79 & 6.96 & 0.45 & 0.33 \\
\hline
\end{tabular}




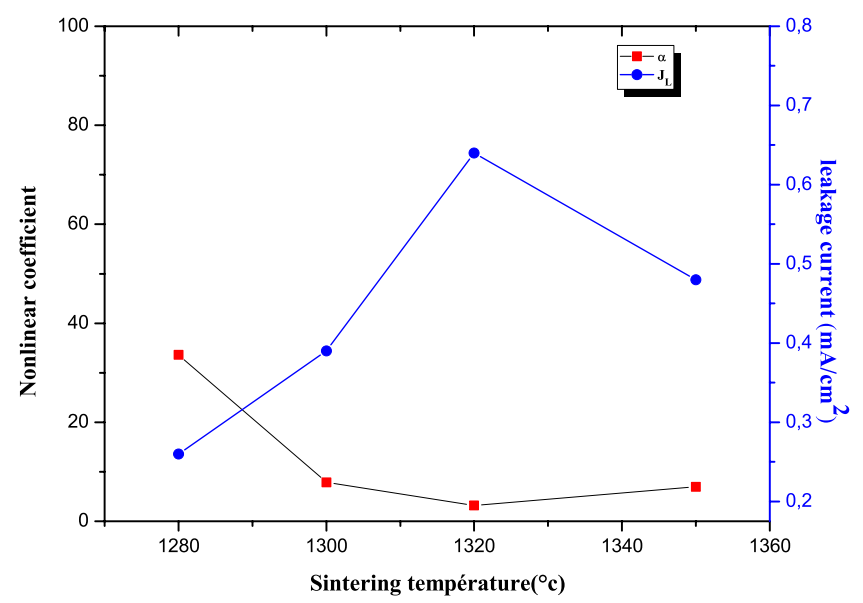

Fig. 2. Variation of nonlinear coefficient $\alpha$ and leakage current $I_{L}$ with different sintering temperature.

phase exists as a minor phase for all the samples. The intensity of these peaks decreases with the increase of sintering temperature. This phase can inhibit the grain growth during the sintering process of the varistor. ${ }^{18}$

\subsection{Current-voltage characteristics}

Figure 5 shows the electric field and current density $(E-J)$ curves of samples with different sintering temperatures. It is clearly seen that all the samples have varistor property. The $(E-J)$ curves of ZBMCCSS-based varistor ceramics can be divided into two regions. The first region is in the low-field, where the varistor is an insulator, which allows low leakage current. The seconde region clearly shows nonlinear behavior (upturn region). The $(E-J)$ characteristic parameters with various sintering temperatures are summarized in Table 1.

The breakdown field $E_{B}$ decreased over a wide range from 2991.57 to $127.84 \mathrm{~V} / \mathrm{cm}$ with the increase of sintering temperature. This fact can be explained by: firstly, the increase in the average grain size, equivalent to a reduction of the number of grain boundaries as shown in Fig. 4. Secondly, the decrease of varistor voltage per grain boundary $V_{\mathrm{gb}}$, as shown in Table 1. In general, smaller the grain size, higher the varistor voltage.

The nonlinearity coefficient $\alpha$ decreased sharply from 33.61 to 7.87 until the sintering temperature is $1280^{\circ} \mathrm{C}$. However, when the sintering temperature exceeded $1300^{\circ} \mathrm{C}$, $\alpha$ increased to a slight extent from 3.19 to 6.96 , the tendency of change in $\alpha$ is very unusual because of sharp change of $\alpha$ between $1280^{\circ} \mathrm{C}$ and $1350^{\circ} \mathrm{C}$. So the sample sintered at $1280^{\circ} \mathrm{C}$ exhibited the breakdown field as high as $2991 \mathrm{~V} / \mathrm{cm}$ and the non-ohmic coefficient as high as 33. For the sintering temperature used in this work, the best value of $\alpha$ was found for FB1 varistor sintered with $1280^{\circ} \mathrm{C}$.

Figure 2 shows the variation of $\alpha$ and leakage current $I_{L}$ as a function of sintering temperature. The variation of $J_{L}$ value

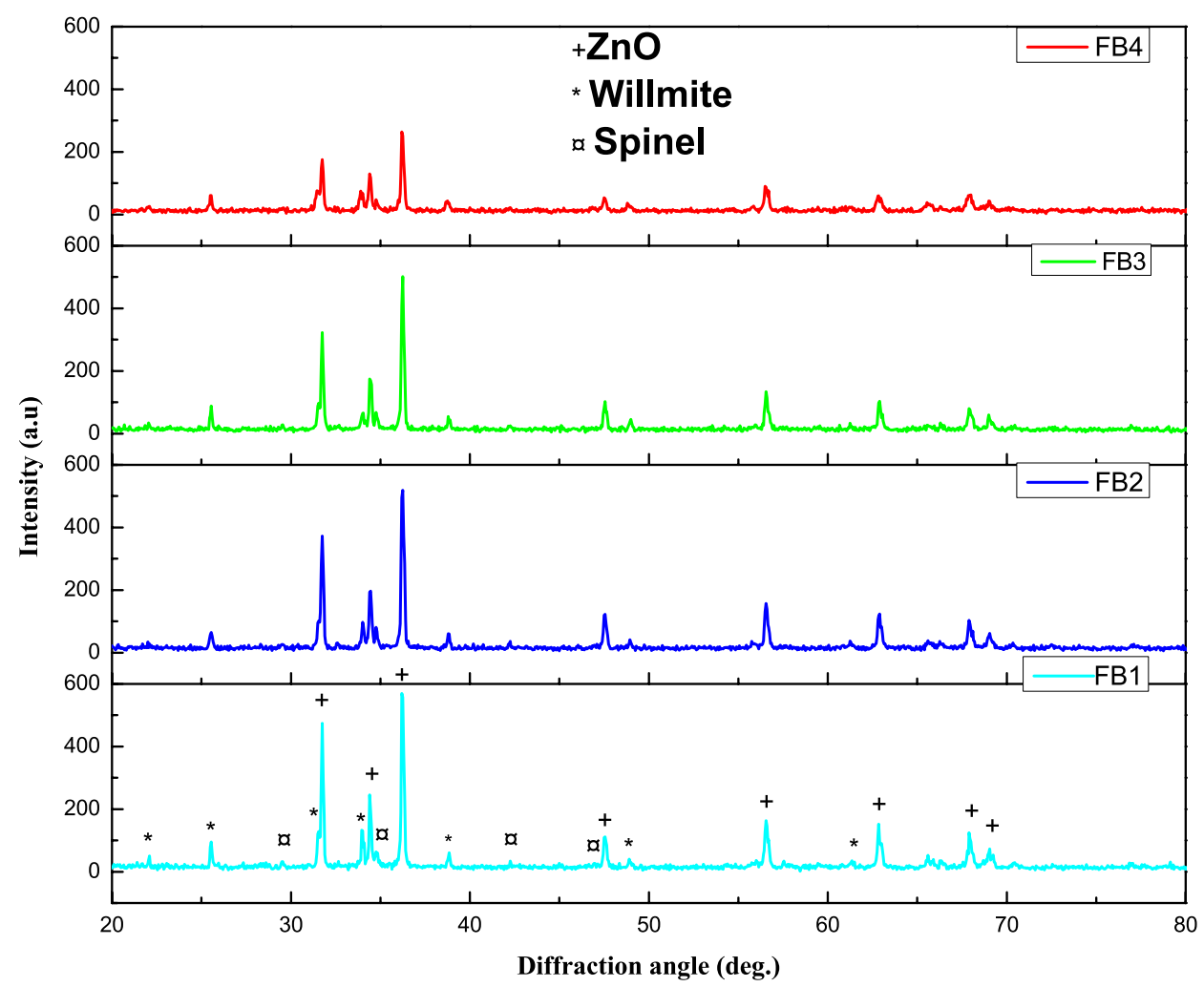

Fig. 3. XRD patterns of the samples for different sintering temperatures. 


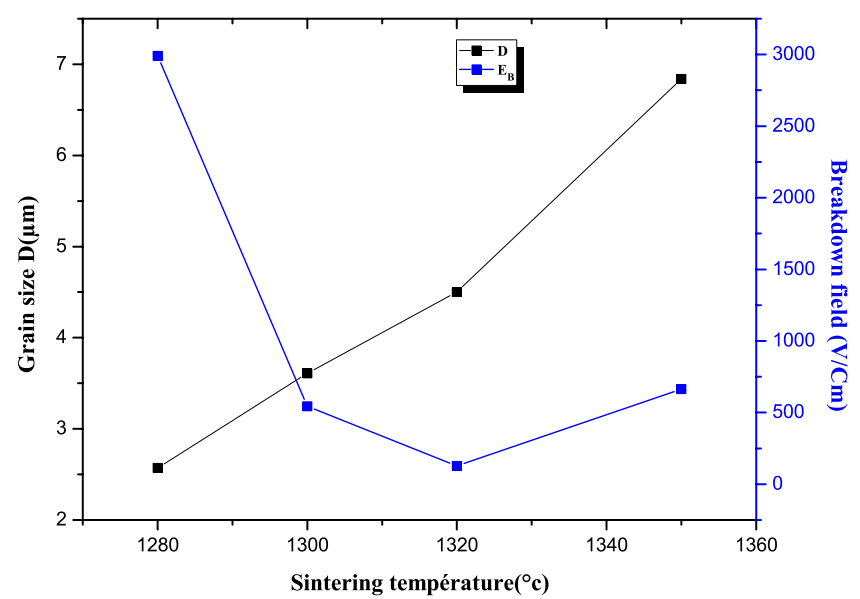

Fig. 4. Variation of grain size $D$ and breakdown field $E_{B}$ with different sintering temperature.

is observed to be opposite to $\alpha$. The minimum value of leakage current $I_{L}$ was found for FB1 varistor ceramic. The $V_{\mathrm{gb}}$ was in the range of 0.76 to $0.06 \mathrm{~V} / \mathrm{gb}$.

Many researchers have been studying the impacts of microstructure, metal oxide additives and processing methods on the degradation of $\mathrm{ZnO}$ varistors. ${ }^{19} \mathrm{Nahm}$ et al. reported the degradation behavior by DC-accelerated stress and pulsecurrent stress of varistors with different sintering temperatures. They have found that the sample sintered at $1300^{\circ} \mathrm{C}$ exhibited the highest stability for $E-J$ characteristics after application of the DC-accelerated stress state and they confirmed that the sintering temperature has a strong effect on degradation behavior by the stress. ${ }^{20}$ The degradation phenomena in $\mathrm{ZnO}$ varistors occurs under ac, dc, and pulse electric field resulting in changes in nonlinear coefficient and leakage current.

As a result, the best sample exhibits low leakage current, high nonlinear coefficient and high breakdown voltage. The

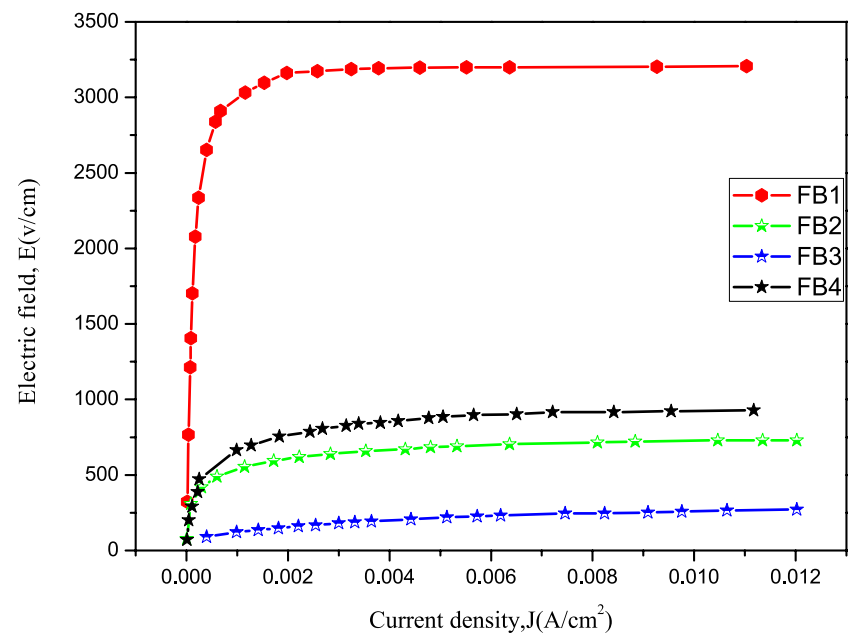

Fig. 5. E-J characteristics of the samples for different sintering temperatures. varistor $\mathrm{FB} 1$ sintered at $1280^{\circ} \mathrm{C}$ is better than $\mathrm{FB} 2, \mathrm{FB} 3$ and FB4. The nonlinear coefficient $\alpha$ is above 33, the breakdown field $E_{B}$ is $2991.57 \mathrm{v} / \mathrm{cm}$, and leakage current is $J_{L}=0.21 \mathrm{~mA} / \mathrm{cm}^{2}$.

\section{Conclusions}

The properties of ZBMCCSS-based varistor prepared by the ceramic method, which was discussed in the preparation section of the samples, were investigated as a function of different sintering temperatures, and investigated for phase identification and grain morphology by using XRD and SEM techniques. The XRD pattern showed the presence of $\mathrm{ZnO}$, $\mathrm{Zn}_{2} \mathrm{SiO}_{4}$ willemite and $\mathrm{Co}_{2.33} \mathrm{Sb}_{2.67} \mathrm{O}_{4}$ spinel.

For sintering temperatures ranging from $1280^{\circ} \mathrm{C}$ to $1350^{\circ} \mathrm{C}$, the average grain size increased from 2.57 to $6.84 \mu \mathrm{m}$, which leads to a substantial decrease in breakdown field of the varistors from 2991 to $127 \mathrm{v} / \mathrm{cm}$. The nonlinearity coefficient $\alpha$ measured for the material sintered at $1280^{\circ} \mathrm{C}$ was 33.61. This coefficient decreased with the increase of sintering temperature.

Finally, it can be inferred from the above results that the ZBMCCSS ceramic varistors sintered at $1280^{\circ} \mathrm{C}$ would be very useful in the fabrication of a good varistor, because, first, they exhibit excellent electrical properties of $2991.57 \mathrm{v} / \mathrm{cm}$, $\alpha=33.61$ and $J_{L}=0.21 \mathrm{~mA} / \mathrm{cm}^{2}$, second, the electrical characteristics of the degraded sample are partially restored after heat treatment in an oxygen-rich atmosphere. Hence, these varistors could be applied to the nonlinear resistors for high-voltage field.

\section{References}

${ }^{1}$ M. Matsuoka, Non ohomic properties of zinc oxide ceramics, Jpn. J. Appl. Phys. 10, 736 (1971).

${ }^{2}$ A. Banerjee and T. Ramamohan, Smart technique for fabrication of zinc oxide varistor, Mater. Res. Bull. 36, 1259 (2001).

${ }^{3}$ E. El-Meliegy and H. I. Saleh, Sintering and characterization of bismuth-oxide containing zinc oxide varistors, Mater. Charact. 10, 52 (2004).

${ }^{4} \mathrm{H}$. Hng and $\mathrm{P}$. Chan, $\mathrm{Cr}_{2} \mathrm{O}_{3}$ doping in $\mathrm{ZnO}_{0.5}$ mol $\mathrm{V}_{2} \mathrm{O}_{5}$ varistor ceramics, Ceram. Int. 75, 61 (2008).

${ }^{5}$ L. Xiangkai Xiao, L. Y. Zheng and T. Tian, Effect of $\mathrm{Cr}_{2} \mathrm{O}_{3}$ on the property and microstructure of $\mathrm{ZnO} \mathrm{Bi}_{2} \mathrm{O}_{3}$ varistor ceramics in different sintering temperature, Ceram. Int. 41, S557 (2015).

${ }^{6} \mathrm{H}$. H. Hng and P. L. Chan, Effects of $\mathrm{MnO}_{2}$ doping in $\mathrm{V}_{2} \mathrm{O}_{5}$-doped $\mathrm{ZnO}$ varistor system, Mater. Chem. Phys. 75, 61 (2002).

${ }^{7} \mathrm{C}$. W. Nahm, Improvement of electrical properties and aging characteristics of Pr-Co-Cr-y-modified $\mathrm{ZnO}$ varistors by $\mathrm{Al}_{2} \mathrm{O}_{3}$ doping, Mater. Sci. Eng. B 151, 146 (2008).

${ }^{8}$ S. Ma, Z. Xu, R. Chu and J. Hao, Influence of $\mathrm{Cr}_{2} \mathrm{O}_{3}$ on $\mathrm{ZnO}-$ $\mathrm{Bi}_{2} \mathrm{O}_{3}-\mathrm{MnO}_{2}$-based varistorceramics, Ceram. Int. 40, 10149 (2014).

${ }^{9}$ C. W. Nahm, The effect of sintering temperature on varistor properties of ( $\mathrm{Pr}, \mathrm{Co}, \mathrm{Cr}, \mathrm{y}, \mathrm{Al})$-doped $\mathrm{ZnO}$ ceramics, Mater. Lett. 62, 4440 (2008). 
${ }^{10}$ J. L. Wangcheng Long, J. Hu and J. He, Effects of cobalt doping on the electrical characteristics of Al-doped $\mathrm{ZnO}$ varistors, Mater. Lett. 64, 1081 (2010).

${ }^{11}$ N. Yongvanich, K. Niyomtrum, C. Chairatanaset and T. Srisethkul, Enhancement of non-linear properties in $\mathrm{SnO}_{2}$ varistors by $\mathrm{ZnO}$ doping, Ceram. Int. 43, S280 (2017).

${ }^{12} \mathrm{G}$. Hu, J. Zhu, H. Yang and F. Wangand, Microstructure and electrical properties of $\mathrm{MgO}$-doped $\mathrm{SnO}_{2}$ varistor ceramics, J. Mater. Sci., Mater. Electron. 25, 2 (2014).

${ }^{13}$ C.-W. Nahm, Microstructure and electrical properties of $\mathrm{ZnOPr}_{6} \mathrm{O}_{11} \mathrm{Bi}_{2} \mathrm{O}_{3}$-based varistor ceramics with sintering changes, J. Mater. Sci., Mater. Electron. 26, 11 (2015).

${ }^{14} \mathrm{~J}$. Wurst and J. Nelson, Lineal intercept technique for measuring grain size in two-phase polycristalline ceramics, J. Am. Ceram. Soc. 55, 109 (1972).

${ }^{15} \mathrm{M}$. Ashraf and A. Bhuiyan, Microstructure and electrical properties of $\mathrm{Ho}_{2} \mathrm{O}_{3}$ doped $\mathrm{Bi}_{2} \mathrm{O}_{3}$-based $\mathrm{ZnO}$ varistor ceramics, Physica $B$ 405, 3770 (2010).
${ }^{16}$ C. W. Nahm, Effect of sintering temperature on microstructure and varistor properties of $\mathrm{Zn}-\mathrm{V}-\mathrm{O}-$ based ceramics incorporated with Mn-Nb-Tb, Trans. Nonferrous Met. Soc. China 25, 4040 (2015).

${ }^{17}$ J. A. Park, Effect of $\mathrm{Al}_{2} \mathrm{O}_{3}$ on the electrical properties of $\mathrm{ZnO}$ $\mathrm{Pr}_{6} \mathrm{O}_{11}$-based varistor ceramics, Physica B 403, 639 (2008).

${ }^{18}$ H. W. Zhongqiu Hua, Liang Dong and S. Peng, Varistor behavior study in undoped tungsten trioxide ceramic, Physica B 406, 2807 (2011).

${ }^{19} \mathrm{R}$. Sendi, A comparative study on degradation characteristics of $\mathrm{ZnO}$ nanoparticles- $\mathrm{Bi}_{2} \mathrm{O}_{3}-\mathrm{Mn}_{2} \mathrm{O}_{3}$ varistors at various ambient sintering processes, Chin. J. Phys. 55, 2605 (2017).

${ }^{20} \mathrm{C}$.-W. Nahm, Degradation behavior by DC-accelerated and pulsecurrent stress in $\mathrm{Co} / \mathrm{Cr} / \mathrm{Y} / \mathrm{Al} / \mathrm{Ni}$ co-doped $\mathrm{ZnO}-\mathrm{PrO} 1.83$-based varistors, Microelectron. Reliab. 55, 565 (2015). 